\title{
Origin of polyps and accompanying sinonasal pathologies in patients with antrochoanal polyp: Analysis of 22 patients
}

\author{
(1) Suha Ertugrul \\ Department of Otorhinolaryngology, Karabuk University Faculty of Medicine, Karabuk, Turkey
}

\begin{abstract}
OBJECTIVE: Solitary, benign soft tissue masses originating at the maxillary sinus and extending to the nasopharynx are called antrochoanal polyps (ACP). The aim of the study was to determine the origins of ACP accompanying sinonasal pathologies and the effectiveness of endoscopic sinus surgery in patients with ACP.

METHODS: Twenty-two patients (13 men, 9 women; age range: 6-50; average age: 28.3 \pm 13.3 ) who were treated for ACP using endoscopic sinus surgery between January 2014 and September 2017 were included in the study. The patient's age, sex, symptom at presentation to the clinic, sinonasal pathologies accompanying the ACP, and adhesion site of ACP inside the maxillary sinus were retrospectively examined.

RESULTS: The most frequently encountered symptom in patients was nasal congestion (95.4\%). This was followed by snoring and sleeping with an open mouth $(31.8 \%)$, nasal discharge $(22.7 \%)$, headache $(18.1 \%)$, feeling of a foreign body in the throat $(9.1 \%)$, and epistaxis (4.5\%). When the adhesion site of ACP in the maxillary sinus was checked, it was seen that it was the most frequently located in the medial wall $(27.2 \%)$, followed by the posterior $(18.1 \%)$ and lateral wall $(13.6 \%)$. One patient (4.54\%) developed recurrence.

CONCLUSION: Although the origin of ACP cannot be detected in the paranasal sinus tomography scan, accompanying sinonasal pathologies should be preoperatively identified. Development of angled endoscopes and angled instruments enabling easy removal of cystic lesions renders endoscopic sinus surgery sufficient for the treatment of ACP.

Keywords: Antrochoanal polyp; endoscopic sinus surgery; nasal obstruction; paranasal sinus.

Cite this article as: Ertugrul S. Origin of polyps and accompanying sinonasal pathologies in patients with antrochoanal polyp: analysis of 22 patients. North Clin Istanb 2019;6(2):166-170.
\end{abstract}

Colitary, benign soft tissue masses originating at the nasal cavity and extending to the nasopharynx are called choanal polyps (CP). They most frequently originate in the maxillary sinus and are termed antrochoanal polyps (ACP) [1]. ACP constitutes $3 \%-6 \%$ of nasal polyps in adults and $28 \%$ in children, with an incidence rate of $1-2 / 10000$ [1]. Although it generally appears as unilateral, bilateral cases have also been reported [2]. The most frequent symptom of ACP is a unilateral nasal obstruction. Nasal endoscopy and computerized to- mography (CT) are sufficient for the diagnosis in most cases. In ACP, a unilateral, grey-white colored mass with a smooth surface extends from the middle meatus to choana [1]. In CT, it is typical for ACP to see a unilateral soft tissue density in the nasal cavity and choana [3]. For differential diagnosis, inverted papilloma, juvenile angiofibroma, olfactory neuroblastoma, nasopharyngeal malignancies, adenoid hypertrophy, nasal polyposis, meningoencephalocele, and turbinate hypertrophies should be considered [1-4]. The most frequently per-

Received: December 17, 2017 Accepted: March 24, 2018 Online: August 08, 2018

Correspondence: Dr. Suha ERTUGRUL. Karabuk Universitesi Tip Fakultesi, Kulak Burun Bogaz Hastalikları, Karabuk, Turkey.

Tel: +90 3704187160 e-mail: drsuhaertugrul@hotmail.com

(c) Copyright 2019 by Istanbul Provincial Directorate of Health - Available online at www.northclinist.com 
formed surgical interventions include endoscopic sinus surgery and Caldwell-Luc operation. In this study, the results of patients diagnosed with $\mathrm{ACP}$ who were treated only using the endoscopic method were evaluated in the light of the literature.

\section{MATERIALS AND METHODS}

Ethical approval for the study was obtained from the ethics committee of our institution. Twenty-two patients with ACP who presented to the Department of Otorhinolaryngology between January 2014 and September 2017 and received endoscopic sinus treatment were included in the study. The patients who had a history of rhinology operation and received a combined surgical intervention, such as trans canine sinoscopy or Caldwell-Luc operation, with endoscopic sinus surgery for ACP were excluded from the study. Following a detailed evaluation of the medical history of all patients, they underwent anterior rhinoscopic examination and endoscopic nasal examination. Paranasal sinus CT scans were performed on the axial and coronal planes. After the sinonasal pathologies accompanying ACP were identified, the patients were taken to the operating theater under general anesthesia. Following uncinectomy, the ACP was being excised along with the cystic part in the maxillary sinus. The adhesion site within the maxillary sinus was determined using 45- and 70- degree telescopes and excision was performed using angled punches. In addition to endoscopic sinus surgery, patients with septum deviation received septoplasty, patients with concha bullosa received lateral lamellar excision, and patients with inferior concha hypertrophy received inferior turbinoplasty and inferior concha radiofrequency interventions. Antibiotics therapy was initiated in the postoperative period. Nasal irrigation using a physiological saline solution was recommended. The control examinations were performed in the first month, sixth month, and first year.

\section{RESULTS}

The age range of 22 patients with ACP included in our study was $6-50$, and their average age was $28.3 \pm 13.3$. Five $(22.7 \%)$ patients were below the age of 18 . In terms of gender distribution, $13(59.1 \%)$ patients were male and $9(40.9 \%)$ were female. The male/female ratio was 1.44 . The most frequently encountered symptom in patients was nasal congestion (95.4\%), followed by snoring
TABLE1. Adhesion site of the antrochoanal polyp in the maxillary sinus

\begin{tabular}{lcc} 
The origin & $\mathrm{n}$ & $\%$ \\
\hline Medial & 6 & 27.2 \\
Posterior & 4 & 18.1 \\
Lateral & 3 & 13.6 \\
Anterolateral & 2 & 9,1 \\
Inferomedial & 2 & 9.1 \\
Posterolateral & 2 & 9.1 \\
Inferolateral & 1 & 4.5 \\
Inferior & 1 & 4.5 \\
Posteromedial & 1 & 4.5
\end{tabular}

TABLE2. Sinonasal pathologies accompanying antrochoanal polyp

\begin{tabular}{lcc} 
Sinonasal pathologies & $\mathrm{n}$ & $\%$ \\
\hline Septum deviation & 14 & 63.6 \\
Concha bullosa & 10 & 45.4 \\
Inferior concha hypertrophy & 8 & 36.3 \\
Maxillary sinusitis & 4 & 18.1 \\
Ethmoid sinusitis & 3 & 13.6 \\
Retention cyst & 3 & 13.6 \\
Paradoxical middle concha & 3 & 13.6 \\
Frontal sinusitis & 1 & 4.5 \\
Septal pneumatization & 1 & 4.5
\end{tabular}

and sleeping with an open mouth (31.8\%), nasal discharge $(22.7 \%)$, headache $(18.1 \%)$, feeling of a foreign body in the throat (9.1\%), and epistaxis (4.5\%). All ACP were unilateral, and $14(63.6 \%)$ of them originated in the left maxillary sinus, whereas $8(36.3 \%)$ of them originated in the right maxillary sinus. The most common adhesion site of ACP in the maxillary sinus was the medial wall (27.2\%), followed by the posterior wall (18.1\%) and lateral wall (13.6\%) (Table 1). ACP extended into the nasal cavity through natural ostium in 19 patients (86.3\%) and through the accessory ostium in 3 patients (13.6\%). When the sinonasal pathologies of patients accompanying ACP were checked, the presence of septum deviation (63.6\%) and concha bullosa (45.4\%) was the most frequent, followed by inferior concha hypertrophy (36.3\%) and maxillary sinusitis (18.1\%) (Table 2). In 5 $(22.7 \%)$ patients, pathology has identified a sinus apart 
from the sinus where ACP was present. Of them, 2 had ipsilateral ethmoid sinusitis; 2 had contralateral maxillary sinusitis; and 1 had ipsilateral ethmoid sinusitis and frontal, contralateral sinusitis. When the 14 patients with septum deviation were examined, it was seen that septal deviation was at the same side as that of ACP in $10(71.4 \%)$ patients and at the side without ACP in 4 (28.5) patients. Concha bullosa was bilateral in 2 patients. In all 8 patients with unilateral concha bullosa, it was observed that concha bullosa was at the side where $\mathrm{ACP}$ was not present. In addition to endoscopic surgery, 13 patients received septoplasty, 8 received concha bullosa lateral lamellar excision, 6 received radiofrequency administration in the inferior concha, 2 received inferior turbinoplasty, 2 received antrostomy of the contralateral maxillary sinus, and 1 received ipsilateral ethmoidectomy and frontal sinusotomy. No postoperative complications were encountered. One patient, whose ACP was identified as originating in the anterolateral wall, developed recurrence at the control visit in the first year. The recurrence rate in cases of ACP treated with only endoscopic sinus surgery was $4.54 \%$. Revision surgery was performed as a combination of endoscopic surgery and Caldwell-Luc operation.

\section{DISCUSSION}

CP was originally described by Killian in the year 1906 [5]. However, its etiology has not yet been fully established. Local reasons, such as ostium obstruction and chronic sinusitis, are considered at the forefront of the etiology. Chronic inflammation and negative pressure occurring in the antrum following ostium obstruction result in the development of a mural cyst at this site. Berg et al. [6] identified that the expansion of an intramural cyst into the nasal cavity was important in the development of CP. According to Myers [7], ACP in children develops in association with bacterial infection and cystic fibrosis. In our study, $22.7 \%$ of the patients were identified to have signs of chronic sinusitis. The association between allergy and ACP is unclear. We did not perform routine allergy tests in our study. Aktas et al. [8] did not identify allergies in any of the cases in their study, whereas Chen et al. [1] identified allergies in $50 \%$ of the patients and Cook et al. [9] identified allergies in $69.7 \%$ of the patients. Turbulent airflow and gravity are also local factors that may play a role in the development of CP [10]. Septum deviation may be a factor in the localization of CP [11]. Septum deviation changes the airflow within the nose. A stronger air current develops in the concave side of the deviated nose as compared to its convex side. This situation may result in the CP being on the concave side of the deviated nose [11]. In our study, $63.6 \%$ of the patients had a septal deviation while $45.4 \%$ had concha bullosa. These high rates support the hypothesis that turbulent airflow may be a factor in the etiology of $\mathrm{CP}$. However, CP was on the convex side of the deviated nose in $62.5 \%$ of the patients with septum deviation and on the concave side of the deviated nose in $28.5 \%$ of the patients. Even though these findings do not support the hypothesis that $\mathrm{CP}$ develops in the side with stronger airflow, the fact that all conchae bullosis were on the side without $\mathrm{CP}$ in all patients with $\mathrm{CP}$ and concha bullosa, two of them being bilateral, supports this hypothesis. We are also convinced that the local factors such as septum deviation and concha bullosa are effective in the etiology of $\mathrm{CP}$ in that they cause the airflow within the nose to become turbulent.

Nasal obstruction is the most frequently observed symptom in patients with ACP. Furthermore, they may also develop snoring, sleep apnea, headache, feeling of a foreign body in the throat, and swallowing problems [12]. Similarly, in our study, the most frequently observed symptom was a nasal obstruction, followed by snoring and sleeping with an open mouth, nasal discharge, headache, feeling of a foreign body in the throat, and epistaxis.

Approximately $>25 \%$ of ACP cases have multiple sinus pathologies. Aktas et al. [8] reported bilateral sinusitis in 6 patients and unilateral pansinusitis in 1 patient in their series of 16 cases. In the study conducted by Altun et al. [13], no sinus pathologies were encountered other than mucosal thickening. In our study, $22.7 \%$ of the patients were identified to have one additional sinus pathology. Balikci et al. [14] identified septum deviation in $50 \%$, inferior concha hypertrophy in $32.5 \%$, and concha bullosa in $17.6 \%$ of patients with ACP. Tatlipinar et al. [15] identified septum deviation in 60.86\%, concha bullosa in $13.04 \%$, inferior concha hypertrophy in $4.34 \%$, and adenoid hypertrophy in $4.34 \%$ of the patients. In our study, septum deviation was seen in $63.6 \%$, concha bullosa in $45.4 \%$, inferior concha hypertrophy in $36.3 \%$, paradoxical middle concha in $13.6 \%$, and septal pneumatization in $4.5 \%$ of the patients.

The cystic part in the antrum may be originating in any of the walls of the antrum. Min et al. [16] reported in their series of 40 cases that ACP originated most 
frequently in the posterior wall and it was followed by inferior, lateral, and medial walls. Kamel [17] specified that the polyp originated in the medial wall in 13 of 22 patients with ACP, whereas the antrum mucosa of the remaining 9 patients was observed to be generally polypous and the originating site of the polyp could not be identified. Balikci et al. [14] reported in their series of $34 \mathrm{ACP}$ cases that the polyp originated in the posterior wall in $85.3 \%$, lateral wall in $5.8 \%$, and medial wall in $5.8 \%$ of the patients. In our study, we reported that the polyp originated in the medial wall in $22.7 \%$, posterior wall in $18.1 \%$, and lateral wall in $13.6 \%$ of the patients with ACP.

ACP extends into the nasal cavity frequently through the natural ostium of the maxillary sinus and rarely through the accessory ostium or a surgical defect $[6,15,18]$. It was observed in our study that the polyp extended through the accessory ostium in only three (13.6\%) patients.

Treatment for CP is surgical excision. Simple avulsion of polyps, Caldwell-Luc operation, and removal of the antral part via inferior meatus are surgical methods that have been applied for many years $[1,16,18]$. Recurrence may amount to $25 \%$ even in cases where the only polyp was removed [18]. To prevent postoperative recurrence, it is important to remove the cystic component in the sinus $[18,19]$. However, Caldwell-Luc operation has disadvantages, such as increased morbidity and negative effect on the teeth and maxilla development, particularly in children, and causing edema and numbness on the face [19]. As for the method of removing the antral part through the inferior meatus, it has disadvantages, such as failure to ensure adequate exposition, causing intranasal adhesions and problem-causing hemorrhages originating in the inferior concha [20]. In CP, endoscopic sinus surgery is of great importance in both diagnosis and treatment. Endoscopic sinus surgery has advantages such as providing the ability to intervene on accompanying sinonasal pathologies, allowing an angled visualization and low morbidity and avoiding dental damage, particularly in children. Another advantage of the endoscopic approach is that the middle meatus antrostomy eliminates the negative pressure within the maxillary sinus, which is a suggested factor in etiology [19]. As for the recurrence rates, the studies where the endoscopic sinus surgery was performed, the recurrence rate was $0 \%-17.3 \%$, whereas the recurrence rate was $0 \%-4.7 \%$ in studies where Caldwell-Luc operation, canine fossa antrostomy, and endoscopic endonasal method were combined with maxillary antrostomy $[9,14,15,17$, 21]. Uslu et al. [19] recommended canine fossa maxillary sinoscopy in addition to endoscopic sinus surgery in case of the smallest doubt and Caldwell-Luc operation in cases where that would not be sufficient. Forceps with different angles and lengths are developed every day and the rates of combined approaches are reduced, thanks to these surgical instruments. In our study, the rate of recurrence in antrochoanal polyp cases treated by only endoscopic sinus surgery was $4.54 \%$. We are convinced that the development of angled endoscopes and angled instruments enabling easy removal of cystic lesions renders endoscopic sinus surgery sufficient for the treatment of ACP. We are of the opinion that "giraffe forceps" is particularly effective against reaching the sites inside the maxillary sinus. It was observed that adequate excision could be performed even in ACP with anterior and inferior wall localization. One case where recurrence was observed developed in the period when we did not have giraffe forceps available to us.

In conclusion, although the origin of ACP cannot be detected in the paranasal sinus CT scan, accompanying sinonasal pathologies should be preoperatively identified. Endoscopic sinus surgery is an effective and reliable method for the treatment of ACP. Endoscopic surgery should be the first-line therapy for the treatment of ACP. Giraffe forceps is very effective in reaching the sites inside the maxillary sinus.

Conflict of Interest: The authors declare no conflict of interest.

Financial Disclosure: The authors declared that this study has received no financial support.

\section{REFERENCES}

1. Chen JM, Schloss MD, Azouz ME. Antro-choanal polyp: a 10-year retrospective study in the pediatric population with a review of the literature. J Otolaryngol 1989;18:168-72.

2. Ozdek A, Ozel HE. Unusual presentations of choanal polyps: report of 3 cases. Ear Nose Throat J 2014;93:10-3.

3. Pruna X, Ibañez JM, Serres X, Garriga V, Barber I, Vera J. Antrochoanal polyps in children: CT findings and differential diagnosis. Eur Radiol 2000;10:849-51. [CrossRef]

4. Yariktaş M, Doğru H, Döner F, Tüz M, Yasan H. Choanal polyp originating from the inferior turbinate presenting as nasal polyposis. Kulak Burun Bogaz Ihtis Derg 2006;16:37-40.

5. Killian G. The origin of choanal polyp. Lancet $1906 ; 2: 81-2$. [CrossRef]

6. Berg O, Carenfelt C, Silfverswärd C, Sobin A. Origin of the choanal polyp. Arch Otolaryngol Head Neck Surg 1988;114:1270-1. [CrossRef]

7. Myers EN, Cunningham MJ. Modified Caldwell-Luc approach for the treatment of antral choanal polyps. Laryngoscope 1986;96:911-3. 
8. Aktaş D, Yetişer S, Gerek M, Kurnaz A, Can C, Kahramanyol M. Antrochoanal polyps: analysis of 16 cases. Rhinology 1998;36:81-5.

9. Cook PR, Davis WE, McDonald R, McKinsey JP. Antrochoanal polyposis: a review of 33 cases. Ear Nose Throat J 1993;72:401-2, 404-10.

10. Bernstein JM, Gorfien J, Noble B. Role of allergy in nasal polyposis: a review. Otolaryngol Head Neck Surg 1995;113:724-32. [CrossRef]

11. Ogawa $\mathrm{H}$. A possible role of aerodynamic factors in nasal polyp formation. Acta Otolaryngol Suppl 1986;430:18-20.

12. Yanagisawa E, Salzer SJ, Hirokawa RH. Endoscopic view of antrochoanal polyp appearing as a large oropharyngeal mass. Ear Nose Throat J 1994;73:714-5. [CrossRef]

13. Altun H, Teker AM, Ceran M, Gedikli O. Endoscopic approach in patients with choanal polyps [Article in Turkish]. Kulak Burun Bogaz Ihtis Derg 2008;18:74-8.

14. Balikci HH, Ozkul MH, Uvacin O, Yasar H, Karakas M, Gurdal M. Antrochoanal polyposis: analysis of 34 cases. Eur Arch Otorhinolaryngol 2013;270:1651-4. [CrossRef]
15. Tatlıpınar A, Gökçeer T, Köksal S, Esen E. Our clinical experience in patients with isolated choanal polyps reaching choana. KBB-Forum 2010;9:25-9.

16. Min YG, Chung JW, Shin JS, Chi JG. Histologic structure of antrochoanal polyps. Acta Otolaryngol 1995;115:543-7. [CrossRef]

17. Kamel R. Endoscopic transnasal surgery in antrochoanal polyp. Arch Otolaryngol Head Neck Surg 1990;116:841-3. [CrossRef]

18. Ryan RE, Neel HB. Antral-choanal polyps. J Otolaryngol 1979;8:3446.

19. Uslu S, İleri F, Sezer C, Asal K, Köybaşığlu A, İnal E. Choanal polyps: origin, microscopy and management [Article in Turkish]. K.B.B. ve Baş Boyun Cerrahisi Dergisi 1999;7:79-84.

20. el-Guindy A, Mansour MH. The role of transcanine surgery in antrochoanal polyps. J Laryngol Otol 1994;108:1055-7. [CrossRef]

21. Eşki E, Imre A, Çallı Ç, Pınar E, Öncel S. Approaches to antrochoanal polyps in adults: long-term comparative results [Article in Turkish]. Kulak Burun Bogaz Ihtis Derg 2012;22:1-5. [CrossRef] 